Utah State University

DigitalCommons@USU

\title{
Intensive Outpatient Acceptance and Commitment Therapy with Exposure and Response Prevention for Adolescents
}

\author{
Julie M. Petersen \\ Utah State University, juliana.petersen@usu.edu \\ Patricia Zurita Ona \\ East Bay Behavior Therapy Center \\ Moorea Blythe \\ The Wright Institute \\ Clara M. Möller \\ The Wright Institute \\ Michael P. Twohig \\ Utah State University, michael.twohig@usu.edu
}

Follow this and additional works at: https://digitalcommons.usu.edu/psych_stures

Part of the Psychiatry and Psychology Commons

\section{Recommended Citation}

Petersen, J. M., Zurita Ona, P., Blythe, M., Möller, C.M., Twohig, M.P. (in press). Intensive outpatient acceptance and commitment therapy with exposure and response prevention for adolescents. Journal of Contextual Behavioral Science.

This Article is brought to you for free and open access by the Psychology Student Works at DigitalCommons@USU. It has been accepted for inclusion in Psychology Student Research by an authorized administrator of DigitalCommons@USU. For more information, please contact digitalcommons@usu.edu.

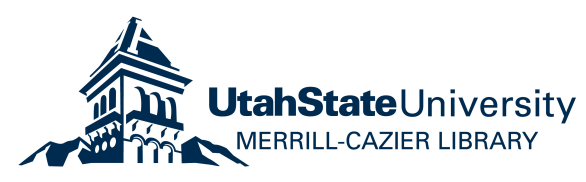


Intensive Outpatient Acceptance and Commitment Therapy with Exposure and Response Prevention for Adolescents

Julie Petersen, M.S. ${ }^{1}$

Patricia Zurita Ona, Psy.D. ${ }^{2}$

Moorea Blythe, M.A. ${ }^{3}$

Clara M. Möller, M.S. ${ }^{3}$

Michael Twohig, Ph.D. ${ }^{1}$

${ }^{1}$ Utah State University, Logan, UT

${ }^{2}$ East Bay Behavior Therapy Center, Walnut Creek, CA

${ }^{3}$ The Wright Institute, Berkeley, CA

Corresponding author:

Julie M. Petersen, M.S.

Department of Psychology

Utah State University

2810 Old Main Hill, Logan, UT 84322

(435) 527-5140

Juliana.petersen@usu.edu 


\begin{abstract}
Intensive treatments for youth obsessive-compulsive disorder (OCD) are important and underresearched. This study used three adolescent cases to assess the preliminary efficacy of an intensive treatment combining acceptance and commitment therapy (ACT) with exposure and response prevention (ERP) for OCD. Participants received intensive treatment for 15 hours per week for three weeks. Assessments were collected at pre-treatment, weekly during treatment, and at posttreatment. All participants ended treatment in the mild range of OCD severity with 32$60 \%$ reductions in symptoms. Participants also reported notable improvements in psychological flexibility and ended treatment in the non-clinical range of depression, anxiety, and stress. These results indicate promise and preliminary support for the use of ACT+ERP in intensive settings for adolescents with OCD. This paper focuses on the clinical application of these techniques. Keywords: acceptance and commitment therapy, obsessive-compulsive disorder, adolescents, intensive treatment
\end{abstract}




\section{Intensive Outpatient Acceptance and Commitment Therapy with Exposure and Response Prevention for Adolescents}

Access to effective, evidence-based treatments for youth struggling with mental health concerns remains a challenge. Because access is often low or otherwise difficult due to life circumstances (e.g., time commitment to treatment, travel for appointments), there is a need to have effective intensive treatment options available. Intensive programs range in their length and format; some involve 14 sessions over two weeks (Storch et al., 2007), sessions twice daily for five days (Whiteside, Brown, \& Abramowitz, 2008), or 16 hours of treatment over the course of one to two weeks (Veale et al., 2016). Intensive treatments allow for individuals to travel and stay near or at evidence-based treatment centers and/or providers for short periods of time rather than making long commutes (Whiteside \& Jacobsen, 2010). Intensive treatments may be especially useful for youth, particularly during school breaks in order to reduce the impact of symptoms on daily life without missing large portions of school or extracurricular activities. Intensive programs may also help sustain motivation in youth where the ability to focus and engage in treatment differs across weeks (Lewin et al., 2005). Intensive treatment formats have been used to treat a range of pediatric anxiety disorders (Gallo et al., 2012) and obsessivecompulsive disorder (Storch, Mariaskin, \& Murphy, 2009; Whiteside et al., 2008; Whiteside \& Jacobsen, 2010).

On the whole, there is a wide base of evidence available supporting the use of intensive cognitive-behavior therapy (i.e., exposure and response prevention; ERP) for both adult and pediatric OCD (Storch et al., 2009). Intensive programs for OCD involve daily or twice daily 90minute sessions, as opposed to a weekly 50-minute approach or the biweekly 90-minute session format of traditional ERP (Foa, Yadin, \& Lichner, 2012). These intensive formats may be especially beneficial for exposure augmentation because intensive exposures are longer and more 
continuous than those in weekly therapy (Lewin et al., 2005). There is also some evidence that greater contact with the therapist in an intensive format may bolster therapy attendance, adherence to skills, and familial involvement in treatment (Deacon \& Abramowitz, 2006; Guo et al., 2020; Whiteside \& Jacobsen, 2010). Furthermore, while traditional outpatient exposure therapy shows promising effects, many youths do not respond to treatment or relapse following standard weekly outpatient care (i.e., ERP and selective serotonin reuptake inhibitors; McGuire et al., 2015). Because OCD is understood to be a chronic and lifelong condition without effective treatment (Micali et al., 2010; Stewart et al., 2004), it is important to investigate more intensive approaches to pediatric OCD treatment, both in the format (i.e., time spent in therapy) and delivery of exposure therapy (i.e., therapeutic adaptations).

While ERP is the well-known, "gold-standard" of OCD treatment for adults and youth (Geller \& March, 2012), remission rates range from 49-53\% in youth (Öst et al., 2016). This high rate of remission may suggest a need for further exploration of treatment options in order to enhance response rates to evidence-based treatment for OCD. In the past two decades, there has been a rise in "third-wave" approaches for the treatment of anxiety and OCD, particularly acceptance and commitment therapy (ACT), as seen in the important review by Bluett and colleagues (2014). More specifically, there is growing support for ACT and ACT-enhanced ERP (Bluett et al., 2014; Twohig et al., 2018) as feasible and effective alternative treatments for OCD in adults and adolescents (Armstrong, Morrison, \& Twohig, 2013; Shabani et al., 2019). However, the research on ERP strongly outweighs the research that is currently available on ACT. Because preliminary findings suggest ACT as a promising alternative and/or treatment enhancer to ERP, it is important to advance the research on ACT as an evidence-based treatment 
option for youth with OCD. Additionally, further research is particularly important given that ERP is not effective for all youth.

In the treatment of OCD, ACT seeks to enhance psychological flexibility by creating new relationships with obsessive thoughts and anxious feelings. The purpose of changing one's relationship with internal experiences is to increase engagement in meaningful activities, rather than trying to decrease the obsession or avoid anxiety. Psychological inflexibility has been repeatedly shown to predict OCD symptoms and mediate OCD treatment outcomes (Ong et al., 2020); ACT is supported in targeting psychological inflexibility and decreasing OCD symptoms and functional impairment (Twohig, Vilardaga, Levin, \& Hayes, 2015). Enhancing psychological flexibility also theoretically aids with elements of ERP such as response prevention and exposure engagement (Twohig et al., 2015), further emphasizing the utility of that ACT can bring to the treatment of OCD. Finally, ACT processes such as acceptance of obsessions are predictive of positive outcomes in traditional ERP in an intensive setting (Reid et al., 2017).

An ACT framework has never been researched as a form of intensive treatment for pediatric OCD. Because of ACT's emphasis on functioning over symptom reduction and its promising offer as an alternative, evidence-based treatment for OCD, it is possible that ACTinformed intensive programs may result in enhanced outcomes as the adolescent returns to daily life. In general, this position is supported by previous work showing psychological flexibility is a key component of fostering exposure exercises (e.g.,Levitt, Brown, Orsillo, \& Barlow, 2004; Reid et al., 2017). An ACT-framework for exposure-based OCD treatment includes values exploration; an adolescent working on values-based exposures may be better equipped to return 
to the routine of daily life following an intensive program of exposures for OCD (e.g., using their values as a motivator for a previously avoided social activity). Increased psychological flexibility via ACT in conjunction with ERP may also provide an adolescent with a greater skill set in responding to OCD; for example, using defusion or acceptance skills to improve their response prevention (e.g., viewing their urges to complete a ritual as separate from themselves, a passing cloud in the sky).

However, little research looks at ACT in intensive formats for clinical concerns in adolescents. In one study, a one-to-three-week intensive ACT-based interdisciplinary pain treatment for adolescents with chronic pain resulted in significant improvements in depression and psychological flexibility, as well as functioning and pain acceptance (Kemani et al., 2018). Another study looked at an intensive 3-day ACT group program for adolescent cancer survivors and found high acceptability (Clarke et al., 2020). These preliminary studies collectively suggest that ACT may be acceptable and effective in intensive formats for youth; thus, it is important to consider how an ACT-framework may be utilized to enhance or bolster intensive treatments for OCD in youth, particularly given that ERP is not considered effective for all youth.

The present study uses three case studies to assess the efficacy of an intensive treatment combining ACT with ERP for adolescents with OCD. We predicted that adolescents would report reduced OCD symptoms, improved psychological flexibility, and reduced overall distress (i.e., depression, anxiety, and stress) following the intensive treatment.

\section{Methods}

\section{Procedure}

To be eligible for the study, participants needed to be an adolescent of 18 years of younger. The participants also needed to have met the diagnostic criteria for OCD as measured 
by the Children's Yale-Brown Obsessive Compulsive Scale (CY-BOCS). Participants also needed to be fluent in English. Participants were not eligible if they did not meet diagnostic criteria for OCD or if they met diagnostic criteria for thought disorders or schizophrenia. The participants were self-referred for intensive outpatient OCD treatment and began treatment at different timepoints (i.e., not simultaneously). Adolescent participants and a parent provided assent and informed consent, respectively, for participation in research.

Upon meeting inclusion criteria, participants commenced intensive outpatient treatment involving sessions lasting three hours a day, 15 hours per week, for three weeks. The structure and length of this intensive outpatient program is comparable to intensive programs from past research (e.g., Storch et al., 2007; Veale et al., 2016). A specific manual was not used for treatment; rather, the treatment was guided based off of the choice point, values-based exposure menu, and unhooking skills log (see Clinical Intervention section). All assessment and treatment sessions took place at [removed for masked review], a private practice setting that provides specialized treatment for anxiety and OCD. The treatment included 12 hours delivered by a licensed clinical psychologist and three hours by a behavioral coach (delivering services under supervision from the licensed psychologist). The licensed psychologist has extensive past experience in providing ACT, ERP, and ACT+ERP for OCD and related problems (e.g., regular professional trainings since 2006, a nominated Association of Contextual Behavioral Science [ACBS] fellow). The two behavioral coaches were psychology doctoral students trained in ACT and ACT+ERP by a minimum of two multi-day trainings. The doctoral students were supervised by the licensed psychologist. Participants completed weekly assessments at pre-treatment, weeks one through three, and post-treatment (i.e., week four). Data were collected at the beginning of 
each week of intensive treatment. Assessments were provided by the licensed psychologist or the behavioral coaches.

\section{Measures}

Children's Yale-Brown Obsessive Compulsive Scale (CY-BOCS; Scahill et al., 1997). The Children's Yale-Brown Obsessive Compulsive Scale (CY-BOCS) is a modified version of the Y-BOCS, which was developed for adults with OCD. Similar to the Y-BOCS, the CY-BOCS is a clinician rated, semi-structured instrument designed to assess the severity of OCD symptoms over the course of the previous week. The CY-BOCS is shown to have high internal consistency and validity (e.g., $\alpha=.87$; Scahill et al., 1997). During the CY-BOCS interview, participants were asked 10 questions about their obsessions and compulsions (e.g., "On average, what is the longest amount of time per day that you are not bothered by obsessive thoughts?", "How long can you go without performing compulsive behavior?"). Clinicians then rate the responses on a scale of 0 (No symptoms/none) to 4 (Extreme). Scores on the CY-BOCS range from 0 to 40 , with scores above eight considered clinical; scores between 8-15 are rated as mild, 16-23 moderate, 24-31 severe, and 32-40 extreme. Based on prior research, treatment responders are those who report greater than or equal to $25 \%$ reduction in scores after treatment (e.g., a reduction of 5 points from an initial score of 20). Furthermore, individuals are considered recovered if they report a $45-50 \%$ or greater score reduction or a score less than or equal to 14 (e.g., a reduction of 10 points from an initial score of 20; Storch, Lewin, De Nadai, \& Murphy, 2010). In the present study, the CY-BOCS was administered by a licensed psychologist or a clinical psychology doctoral student. The doctoral student was trained and supervised in CY-BOCS delivery by the licensed psychologist. 
Depression, Anxiety, Stress Scale - 21 (DASS-21; Crawford \& Henry, 2003). The DASS-

21 is a measure of recent distress (i.e., distress within the last week) with subscales divided into questions related to depression, anxiety, and stress. Participants are asked to rate 21 items on a 4point Likert scale $(0=$ Did not apply to me at all, $4=$ Applied to me very much or most of the time). Example items include "I felt that I had nothing to look forward to" and "I felt I was close to panic." The DASS-21 has acceptable reliability for all scales and the DASS-21 also possesses adequate convergent and discriminant validity when compared to other similar measures (Crawford \& Henry, 2003). The DASS-21 was originally normed on adult population but has established reliability and validity for the DASS-21 total and subscales in adolescent populations around the world (e.g., $\alpha=.72$ - .91 across total and subscale scores; Le et al., 2017; Willemsem et al., 2011).

The DASS-21 is scored in three separate subscales and final scores are doubled to be comparable to the full DASS scores (Lovibond \& Lovibond, 1995). Depression scores of nine and above are considered clinical, with 10-13 indicating mild symptoms, 14-20 moderate, 21-27 severe, and greater than 28 as extremely severe. For anxiety, scores of seven and above are considered clinical, with 8-9 rated as mild, 10-14 as moderate, 15-19 as severe, and greater than 20 extremely severe. Lastly, stress scores greater than 14 are considered in the clinical range, with 15-18 rated as mild, 19-25 moderate, 26-33 severe, and greater than 34 extremely severe. Previous research has established $22-33 \%$ changes in subscale scores indicate clinically relevant change (Ronk, Korman, Hooke, \& Page, 2013).

The Avoidance and Fusion Questionnaire for Youth (AFQ-Y; Greco, Lambert, \& Baer, 2008). The AFQ-Y is a measure of youth psychological inflexibility, specifically cognitive 
fusion and experiential avoidance, in which participants rate 17 items on a five-point Likert scale $(0=$ Not at all true, $4=$ Very true $)$. Scores range from 0-68 with higher scores indicating elevated psychological inflexibility. Some example items include statements such as "My life won't be good until I feel happy" and "I stop doing things that are important to me whenever I feel bad." Items on the AFQ-Y have adequate internal consistency reliability and good convergent and construct validity ( $\alpha=.90$; Greco, Lambert, $\&$ Baer, 2008). The AFQ-Y is a measure of therapeutic process and is intended to measure changes in psychological inflexibility throughout treatment.

\section{Clinical Intervention}

Overall Goals. Given the severity of the OCD symptoms for these three participants and the fact that one-hour weekly therapy sessions would likely need to occur across very long timespans in order to be effective, shorter but more intensive and compact interventions intuitively seemed more practical. As such, the goal of the current treatment was to facilitate generalization of exposure learning, provide ongoing coaching from the therapist as treatment progressed, and promote general well-being in a compact period of time.

Session one and two. Teens were invited to identify their values and discuss how OCDrelated behaviors affected their ability to live their values in different areas of their lives. The purpose of treatment was then clarified as "doing more of what is important while learning unhooking skills to make room for obsessions." Two or three activities were then conducted to help teens to identify their values. For example, adolescents were asked to identify and imagine someone giving a speech on their $21^{\text {st }}$ birthday. Participants were then prompted to imagine what they would want that person to say about them or how they personally imagined themselves at 
21. Who would they want to be in attendance at their party and/or giving that speech? In another exercise, the therapist asked the client to close their eyes and describe an authentic and/or sweet moment with their friends in detail. Adolescents were then asked to describe what was happening during the chosen moment using all five senses and connected the moment to their own broader sense of vitality. It is important to clarify that these activities were more focused on the process of finding what matters and getting in contact with a sense of the vitality, engagement, and fulfillment, rather than finding the "perfect value."

Adolescents were then introduced to tracking their compulsions via a basic selfmonitoring form with the eventual goal of modifying, reducing, and decreasing their compulsions over time. Adolescents were also given the option to use whatever method was most helpful to them for tracking compulsions (e.g., using an app on their phones).

Session three. The Choice Point (See Figure 1; Zurita Ona, 2019) was used as a model to introduce ACT processes and create a context of change for every exposure exercise throughout treatment. The Choice Point graphic was intended to teach the adolescents how to use choosing skills in order to live the life they want to live.

When working with the Choice Point graphic, participants were encouraged to start at the bottom and work upwards to the top. At the bottom of it, adolescents were invited to identify a specific activity based on what matters to them (e.g., playing sports, reading a book, hanging out with a friend, watching a movie). Next, adolescents wrote down all the obsessions that could potentially pop into their mind during that activity. At that point, as happens in real life, the Choice Point graphic reminded them that they have an opportunity to make a choice. Participants then discussed how they could choose to move towards what they care about or away from it. 
On the left side of the Choice Point graphic, adolescents then wrote down all the things they have done to suppress, minimize, distract, and get rid of the unsolicited obsessions. They were asked to consider how these behaviors hooked them and/or took them away from what they care about (via compulsions or avoidance). On the right side of the graphic, adolescents gradually added the skills they learned to get unhooked from those obsessions and take actions toward the values or things that are important to them (e.g., via acceptance, defusion, committed action, exposure exercises). The right side of the graphic was added to over the course of treatment.

The concept of the Choice Point was introduced through an experiential yoga posture. This physical exercise demonstrated that, in order to find balance in the yoga posture, we needed to intentionally choose what we pay attention to and how to position our body. This exercise acted as a physical metaphor that captured the process of choosing how to handle internal struggles (e.g., how they want to respond when facing their fears in an exposure). Adolescents were guided through the yoga pose on each side of the body with the following script: Stand up and press both of your feet against the floor. Extend both of your arms as if you are touching the roof. When you are ready, shift your balance to your left leg. What do you notice your mind saying right now? How does your body feel? Now, if you are willing, cross your right ankle over your left thigh. Your right knee should be open to the side... Notice how it feels to balance your body in one leg. Notice what your mind wants you to do. Next, push your hips back and bend your left knee to lower into a squat, reaching your arms in front of you as you get lower. What do you notice in your body and mind right now? Now, when you are ready, we are going to switch to the other side. 
Following the yoga posture, adolescents described their experience and discussed how it was related to their choice point and exposure practices.

Session three to four. A values-based exposure menu was developed to map out different types of values-based exposure activities the adolescents were willing to do. The values-based exposure menu covered both exposures and response prevention. At this point, the adolescents were aware of specific behaviors that kept them hooked on the obsession (compulsions and avoidance), the consequences/workability of those actions in their life and in regard to their values, and the frequency of their compulsive behavior. These two sessions therefore focused on developing a values-based exposure menu that mapped on to specific OCD symptoms (i.e., compulsions and obsessive thinking), identified their consequences, and recognized the adolescents' values. The adolescent and therapist collaboratively developed values-based exposure activities that were attainable in the adolescents' day-to-day life (e.g., resisting washing by 1-2 times daily, cooking with raw meat even if obsessions about contamination show up). The adolescent and therapist used the values-based exposure menu as a method for tracking frequency of exposure practice as well (e.g., recording date, number of times it was practiced). See Figure 2 for examples of values-based exposure menus.

Remaining sessions. From that point, in every session, adolescents were introduced to various unhooking skills (e.g., acceptance, defusion, management of compulsions) and practiced them in session during exposure exercises. The adolescents chose an exposure activity from their values-based exposure menu for practice with the new skill. The therapist and adolescent worked together to establish what activity and for how long they engaged in this activity. These skills were tracked in the "unhooking log" so that adolescents were aware of the skills they learned and 
could keep track of them. See Figure 3 for an "unhooking log" with some example skills taught during treatment. Response prevention was integrated throughout treatment as a part of these skill building exercises and exposures (e.g., gradually reducing hand sanitizer use during feared, values-based activities like shaking the hand of someone new).

During the values-based exposure exercises, the clinician prompted clients to notice and describe the experiences they were having: "What is showing up in your mind right now? How does it feel to be doing $\mathrm{X}$ while having those obsessions? Are you watching the obsessions? Are you getting hooked or unhooked right now?" If the client reported having an urge to do a compulsion, the clinician reminded the adolescent of their Choice Point and invited the client to step back and notice how that struggle feels, check the consequences of acting on those urges, and use an unhooking skill. During the exposures, willingness level or subjective units of distress (SUDs) were not recorded; instead, therapists encouraged clients to track internal processes and their responses to these processes in a more naturalistic manner (e.g., What is the size of that emotion? Are you holding that thought lightly? Are you making room for that feeling or are you powering through it?).

At the end of every exposure session, there was a reflective time to discuss how the exposure went and how the adolescent handled it. Clinicians and adolescents discussed whether they were fighting internally with the obsessions, whether they got closer or further away from the stuff they care about, and whether they used any control strategies during the exposure practice.

To help the reader to conceptualise how these tasks may have been carried out during the intervention, an illustrative example will be provided. Imagine that a client chose to work on driving even while harm related obsessions appear, an item from his values-based exposure 
menu that was aimed at improving his ability to "be real with others" (values-based exposure). Next, he selected "scrambling obsessions" from his unhooking log, which he identified as an activity to help him further defuse from an obsession that was interfering with his relationships (e.g., his ability to drive somewhere to see friends). He first practiced identifying the obsession specifically, "What if I hit pedestrians and don't even know because I'm not careful enough?" Then, when putting into action the unhooking skill of "scrambling obsessions" he re-wrote and read the obsession as below:

“if not pedestrians I don't careful what if enough because hit I'm even what What not careful what if pedestrians not enough don't I even hit what because Because pedestrians not if I'm not even careful if not hit not enough I'm don't'

Homework planning. At the end of each session, there was a collaborative discussion and planning of exposures-on-the-go for the week using the values-based exposure menu as a guide. The purpose of the exposures-on-the-go was to facilitate the adolescent's experiential learning so they could practice the Choice Point in the service of their values and to ensure that clients were engaging in exposures outside of the scheduled intervention times. When discussing the exposures-on-the-go for the week, the focus was primarily on the adolescent's willingness to have an obsession and how they planned to approach a situation that mattered to them. The therapist and participant planned at least one exposure per day and then reviewed how the exposures went in the following sessions (e.g., what was challenging, what was manageable, what did the adolescent learn). Specific completion rates of exposures on-the-go were not collected; however, anecdotally, therapists observed a 55-70\% completion rate.

Working with families. The majority of treatment was directly with the adolescent, rather than their family. However, most of the teens were receiving accommodations and/or 
reassurance from their parents, caregivers, or friends; when that was the case, an open conversation about those behaviors, their impact on the adolescents' life in the long run was discussed in detail. In certain cases, parents were invited to join one of the adolescent's sessions to discuss these behaviors.

Adolescents and therapists developed a plan for adolescents to coach their parents on what to do instead of giving reassurance or making accommodations. Participants then wrote a letter to their parents on how to modify familial accommodations. The letter included which specific family accommodations were to be removed and what responses they would like from parents instead (e.g., "I may cry and beg you to tell me that things are safe, that I'm okay or will be okay. Please don't do that. Just remind me to use my skills. If I ask you more than three times, please tell me that you cannot answer my questions and that you will leave me some time alone to practice skills.")

\section{Results}

Figures 4-6 detail scores for all participants across all timepoints. Table 1 details aggregate scores for all participants at pre-treatment and posttreatment, and Tables 2 and 3 detail participant scores for the C-YBOCS, AFQ-Y, and the DASS-21 for pre-treatment and posttreatment. As consistent with past OCD treatment literature, percentage changes were calculated by taking the number of points the score decreased by, divided by the initial score, and multiplied by 100. Reliable change was calculated for OCD severity (6.56) using the standard statistical method (Jacobson \& Truax, 1991) using standard deviations and reliability from relevant previous research (Lewin et al., 2014).

Participants one and two were both male, ages 15 and 12 respectively, and Participant three was a 16-year-old female. Participants one and three both identified their nationalities as 
American, and Participant two identified as Chinese. Participants one and three both identified as White, non-Hispanic, and participant two identified as Asian. OCD was the primary diagnosis for all three participants, although some reported depressive symptoms directly related to their OCD symptoms. Participants were not participating in any other psychological treatment, but two reported taking stable doses of selective serotonin reuptake inhibitors (Prozac, Zoloft).

\section{Participant one}

Participant one (P1) scored a total CY-BOCS of 26 at pre-treatment, representing a severe level of OCD symptoms; subscales for obsessions and compulsions each scored at a 13. At posttreatment (i.e., one month since pre-treatment), P1 reported a CY-BOCS score of 17.5, a $32 \%$ decrease (8.5 total points) since pre-treatment and in the moderate range of OCD severity. This 8.5 decrease also indicated reliable change in OCD severity. In terms of psychological flexibility, P1 began IOP treatment with an AFQ-Y score of 31, representing a clinical level of psychological inflexibility. At posttreatment, P1 declined to an eight, a 74\% decrease (23 total points) in psychological inflexibility. Lastly, P1 began treatment with a total DASS-21 score of 66: 22 on the depression subscale, 14 on the anxiety subscale, and 30 on the stress subscale. These scores represent severe depression, moderate anxiety, and severe stress. At posttreatment, P1 had a total DASS-21 score of 22, representing a $66.67 \%$ decrease (44 total points). He reported normal levels of all subscales: depression (eight points), anxiety (two points), and stress (12 points).

\section{Participant two}

At pre-treatment, participant two (P2) scored a total CY-BOCS of 27, representing a severe level of OCD symptoms; subscales for obsessions and compulsions scored at 13 and 14 respectively. At posttreatment, P2's CY-BOCS had declined by $44.4 \%$ to a 15 (12 point 
decrease), with scores of 7.5 on both obsessions and compulsions subscales, ending treatment in the mild range of OCD severity. With the 12 point reduction in CY-BOCS scores, $\mathrm{P} 2$ also experienced reliable change in OCD severity. In terms of psychological inflexibility, P2 began IOP treatment with an AFQ-Y score of 29, also a clinical level of psychological inflexibility. At posttreatment, P2 ended treatment with a score of $11-\mathrm{a} 62 \%$ decrease (18 total points). Lastly, P2 began treatment with a total DASS-21 score of 32: 12 on the depression subscale, six on the anxiety subscale, and 14 on the stress subscale. These scores represent mild depression and normal levels of anxiety and stress. At posttreatment, P2 had a total DASS-21 score of eight (a 16 point decrease), representing low levels of depression (zero points), anxiety (two points), stress (six points) and a $75 \%$ total decrease.

\section{Participant three}

At pre-treatment, participant three (P3) scored a total CY-BOCS of 30, a severe level of OCD symptoms; subscales for obsessions and compulsions each scored at a 15 . At posttreatment, P3's CY-BOCS declined by $60 \%$ to a 12 (an 18 point decrease), with a seven on obsessions and five on compulsions subscales, ending treatment in the mild range of OCD severity. Similar to P1 and P2, P3 also experienced reliable change in OCD severity. In terms of psychological flexibility, P3 began IOP treatment with an AFQ-Y score of 55, a high clinical level of psychological inflexibility. At posttreatment, P3 had a total 85\% decline to an eight (a 47-point decrease). Lastly, P3 began treatment with a total DASS-21 score of 56: 16 on the depression subscale, 16 on the anxiety subscale, and 24 on the stress subscale. These scores represent moderate depression, and severe levels of anxiety and stress. At posttreatment, P3 had a total DASS-21 score of eight, $85.71 \%$ decrease (48 total points). She reported a zero in depression, a low normal level of anxiety (two points), and normal levels of stress (six points). 


\section{Discussion}

This study presents a promising case series for an intensive program utilizing an ACT+ERP framework for the treatment of adolescent OCD. All participants ended treatment in the mild to moderate range of OCD severity with 32-60\% reductions on their CY-BOCS scores from pre- to post-treatment. As previously noted, clients are considered treatment responders if they experience greater than or equal to $25 \%$ reduction on CY-BOCS scores and they are considered recovered if they experience $45-50 \%$ or greater reduction on their CY-BOCS or a score less than or equal to 14 (Storch, Lewin, De Nadai, \& Murphy, 2010). Thus, participants were aggregately and individually considered responsive to treatment, with P3 achieving full remission and P2 almost achieving full remission. All participants also experienced reliable change in CY-BOCS scores. In terms of psychological inflexibility, participants ended with an average of nine on the AFQ-Y. This score represents a reduction of $76 \%$ compared to the start of treatment. Lastly, all participants ended treatment in the normal range of depression, anxiety, and stress according to the DASS-21. All participants were also considered recovered based previously established criteria for the DASS-21 (22-33\% changes in symptoms; Ronk, Korman, Hooke, \& Page, 2013).

In addition to the results from the self-report and interview measures, the clinicians also observed significant changes in adolescent functioning (e.g., the adolescents were able to spend more time hanging out with their friends, attending gatherings, participating more in school) and values-based action. For example, one adolescent was avoiding spending time with his parents for fear of stabbing them; at the end of treatment, he was able to spend quality time with them and even began to cook them meals using knives. As another example, an adolescent had been refusing to play basketball, something they enjoyed, for fear of somebody "stealing their 
knowledge." With treatment, they were able to play basketball again. In general, the clinicians also observed broad improvements in avoidance (e.g., refusal to watch commercials or television related to the LGBTQ+ community, avoidance of attending sporting games unless with one's parents, refusal to use public bathrooms) and rituals (e.g., cleaning credit card after using it, hand sanitizer use, parental accommodation such as specific rules for parental washing) towards valued action and behaviors adolescents found meaningful (e.g., being able to watch shows, attend games without a safety person, eat at restaurants, try new foods). While these outcomes are purely observational, they highlight positive effects from treatment.

Results of the current study add to the growing pool of studies utilizing ACT-based approaches for adolescents with OCD and related disorders and to the general evidence of efficacy for ACT-enhanced ERP (Bluett et al., 2014). These results were consistent with previous studies examining ACT and ACT+ERP for both adults (Twohig et al., 2018) and youth (Armstrong et al., 2013; Shabani et al., 2019). More specifically, the three adolescents in this case series even reported slightly greater percentage reductions (32-60\%) in OCD symptoms than the previous case series on outpatient ACT for OCD in youth (12.5-50\%; Armstrong et al., 2013). The adolescents in the present study also reported greater or comparable improvements in psychological inflexibility, depression, and anxiety over the course of treatment as compared to past studies (Armstrong et al., 2013; Shabani et al., 2019).

This study also presents a unique format for introducing ACT skills and psychological flexibility to youth via the Choice Point (Zurita Ona, 2019), a tool that fosters the ability to choose how to respond to uncomfortable private experiences (obsessions), navigate them (unhooking skills), and choose a workable behavior (values-based behaviors). This tool, to the best of the authors' knowledge, has not been researched before in adolescents with OCD, 
suggesting a promising new clinical tool in need of further empirical exploration. Lastly, very little research has examined ACT in an intensive format, particularly for patients with OCD and/or adolescents; however, these three cases suggest that ACT can be applied successfully in an intensive format, similar to previous research in other clinical samples of youth (Clarke et al., 2020; Kemani et al., 2018).

Whilst the current study represents a very promise avenue of future research, several limitations should also be outlined. First, the subscales of the DASS-21, while normed on adolescents, were originally created for adult populations (Shaw, Campbell, Runions, \& Zubrick, 2017); future research should consider utilizing measures specific for adolescents to better capture symptom change. Assessments were also not delivered by an independent evaluator, pointing towards possible bias in the CY-BOCS results (e.g., participants could have been trying to please the evaluator, potential evaluator scoring bias). Furthermore, a specific manual was not followed and data on treatment fidelity was not collected or recorded, thus limiting knowledge on how accurately the treatment was delivered.

Similar limitations include the absence of other important data. First, extended baseline and follow-up data were not collected for participants, thus limiting the knowledge of how each participants' symptoms may naturally change over time outside of the intervention. As another example, subjective units of distress (SUDS) and/or willingness level during exposure exercises were not recorded, thus making it difficult determine how challenging exposures were and if the level was similar across participants. The collection of SUDS and/or willingness may also have provided insight into whether covert safety behaviors and/or self-reassurance was occurring. Similarly, homework completion rates of exposures on-the-go were not collected; homework completion rates would better inform the results (e.g., whether homework completion enhanced 
post-treatment results). Next, the present study did not collect parental data. Because adolescent and parental data often differs, having parental data would provide another perspective on the symptom change in adolescents (i.e., perhaps would have validated the improvements or showed less improvement than reported by the adolescent). Future research should more closely examine the role of parents in ACT+ERP for OCD in adolescents. Finally, the present study lacks selfreport data on functional impairment or values-based action. These are two important variables in the use of ACT and/or intensive treatment. While the present study provides anecdotal descriptions of adolescent improvement, self-report data is missing in these two areas, and it would be beneficial to collect the adolescents' own perspectives throughout treatment.

Lastly, the sample size of the present size is very small; larger and more diverse research studies are needed with a randomized and/or control group element in order to better support the use of ACT-enhanced, intensive ERP. Such studies would add to the growing evidence base supporting the use of ACT+ERP and provide greater information on how effective intensive ACT+ERP is in comparison to a control or treatment as usual (e.g., standard or intensive ERP formats). Because ACT has been widely supported across mental health conditions and typical clinical settings as an effective form of therapy (Gloster, Walder, Levin, Twohig, \& Karekla, 2020), future research on ACT in an intensive format seems like a promising avenue for further exploration. In order to grow an understanding of how effective ACT can be across settings and severity levels, implementation trials of ACT may be especially useful for integrating ACT effectively and scientifically into intensive and partial hospitalization programs. In this way, the utility of ACT can be better understood (i.e., when it works best and for whom) and it can therefore be implemented effectively for groups who need it the most. 
In summary, this study utilized a case study format to test the effectiveness of ACTenhanced ERP for three adolescents with OCD. This study has demonstrated early potential for the use of ACT frameworks in intensive formats for OCD. Despite many limitations, this study provided promising preliminary data in using a new intensive format and presentation of ACT+ERP for adolescent OCD. It is important for future studies to examine intensive ACT+ERP on a greater scale for adolescents with OCD in order to add to the growing base of evidence supporting the use of ACT and ACT-based treatments for OCD and related concerns. 
Figure 1

The choice point graphic for the start of treatment

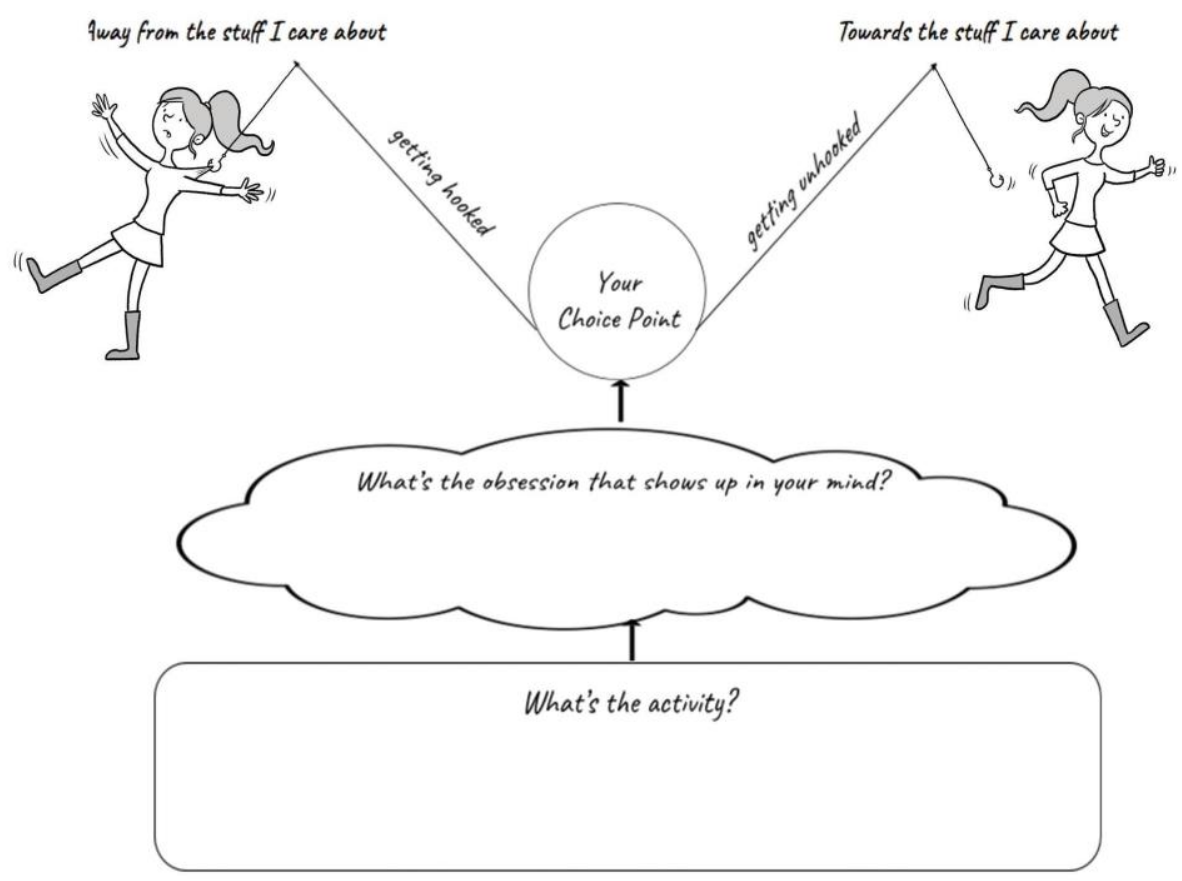

Feeling exhausted, tired, missing time to relax and hang out with friends Away from the stuff I care about
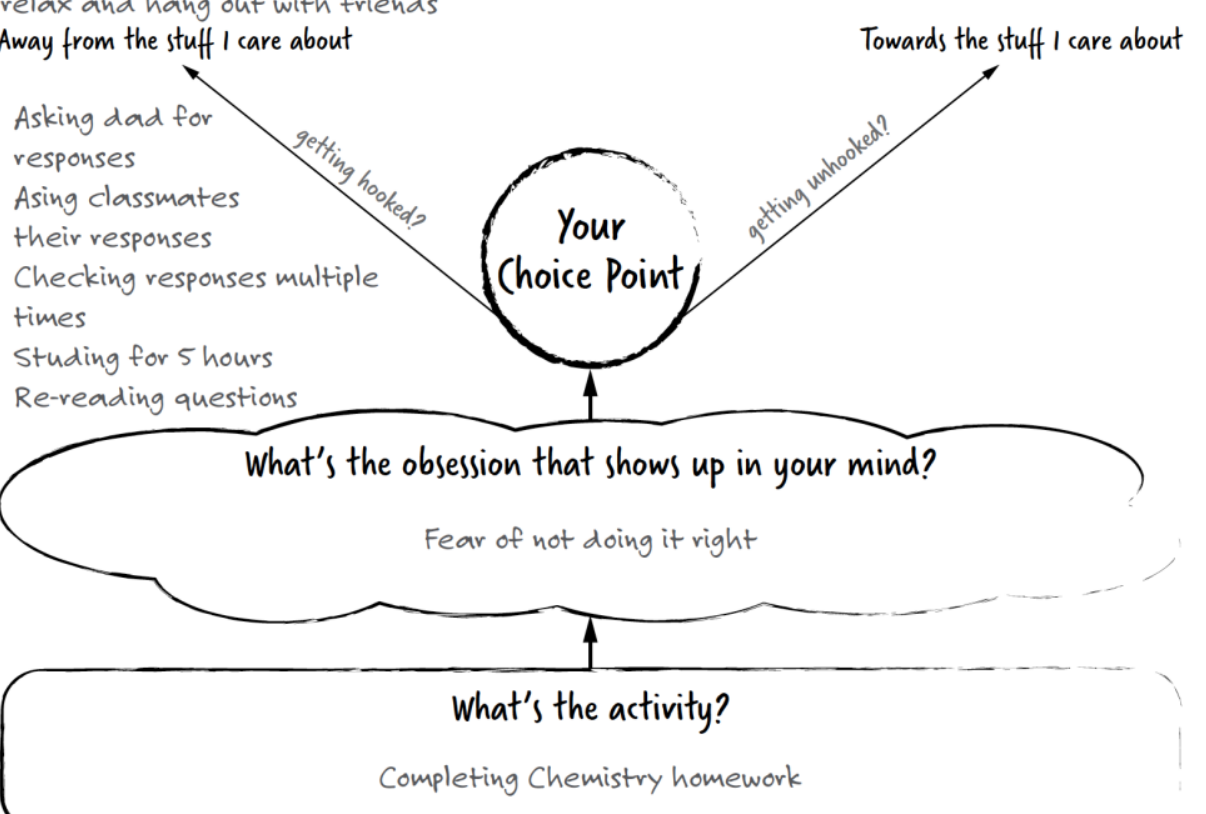
Figure 2

\section{Values-based exposure menu example.}

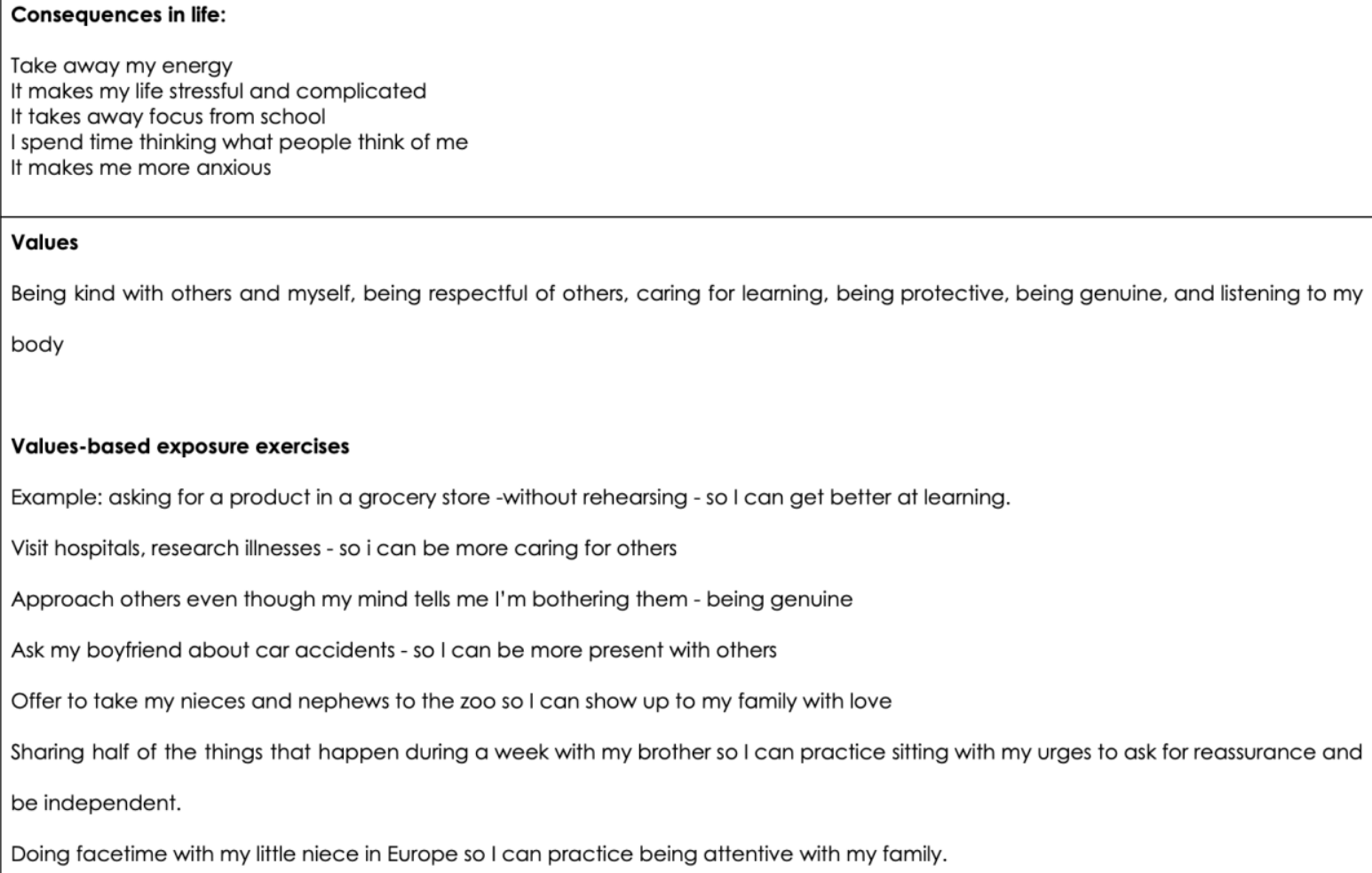


Figure 3

Examples of unhooking skills

Unhooking Log

\begin{tabular}{|l|l|l|l|l|l|l|l|}
\hline \multicolumn{1}{|c|}{ Unhooking Skill } & Monday & Tuesday & Wednesday & Thursday & Friday & Saturday & Sunday \\
\hline $\begin{array}{l}\text { Picturing and giving it a } \\
\text { name }\end{array}$ & & & & & & & \\
\hline $\begin{array}{l}\text { Watching your obsessions } \\
\text { in front of you }\end{array}$ & & & & & & & \\
\hline $\begin{array}{l}\text { Watching your obsessions } \\
\text { in-action }\end{array}$ & & & & & & & \\
\hline $\begin{array}{l}\text { Writing down your } \\
\text { obsessions }\end{array}$ & & & & & & & \\
\hline Saying your obsessions & & & & & & & \\
\hline Teasing your obsessions & & & & & & & \\
\hline $\begin{array}{l}\text { Standing your feet against } \\
\text { compulsions }\end{array}$ & & & & & & & \\
\hline $\begin{array}{l}\text { Hanging in there with } \\
\text { those awful feelings }\end{array}$ & & & & & & & \\
\hline $\begin{array}{l}\text { Agreeing to get out of } \\
\text { your safety zone }\end{array}$ & & & & & & & \\
\hline $\begin{array}{l}\text { Messing around with } \\
\text { compulsions }\end{array}$ & & & & & & & \\
\hline
\end{tabular}




\section{Figure 4}

OCD symptom severity scores for all participants over time.

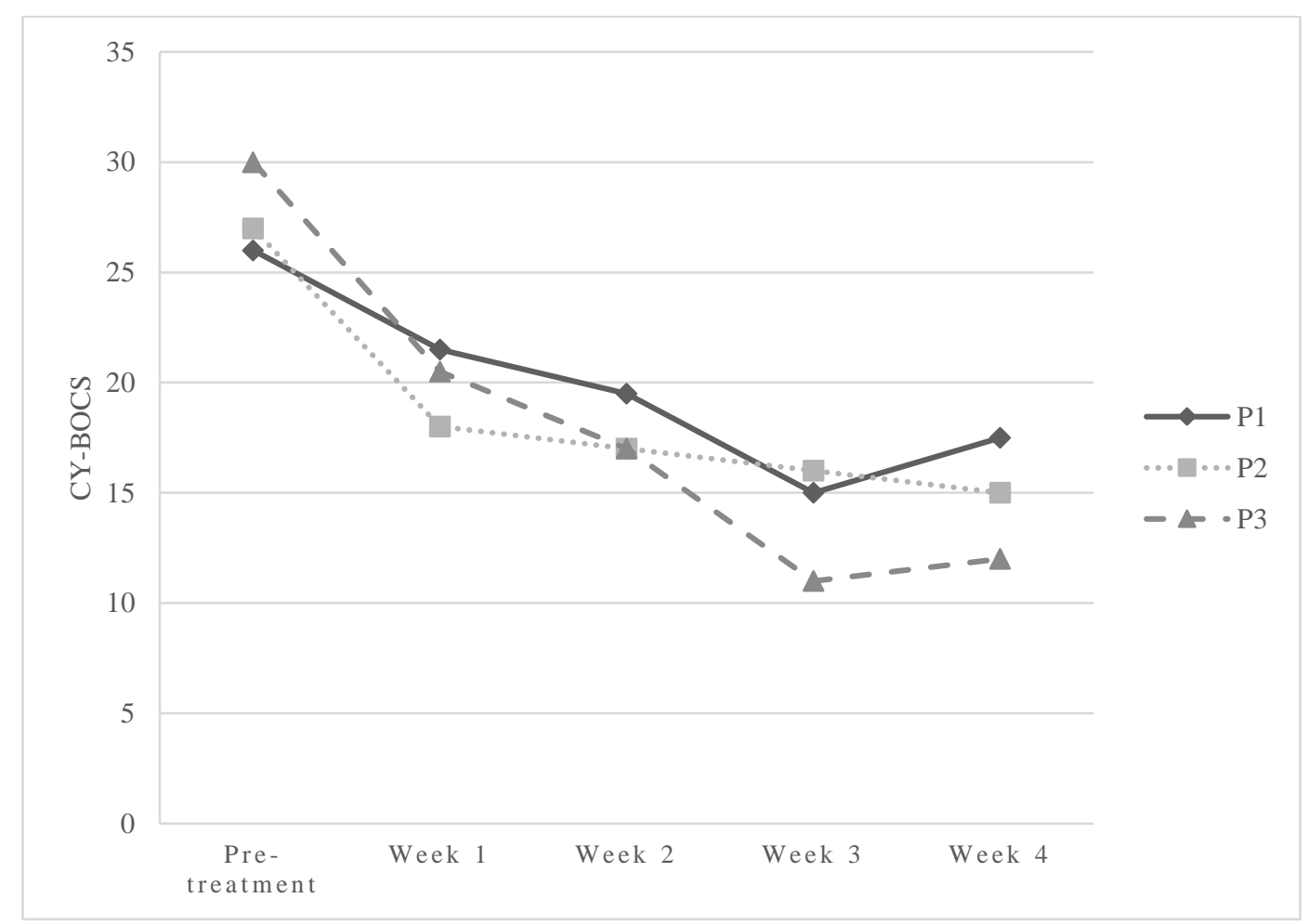

Note. CY-BOCS scores range from 0 to 40 . Greater than 8 is considered within clinical range. Scores between 8-15 are rated as mild, 16-23 moderate, 24-31 severe, and 32-40 extreme. 
Figure 5

$A F Q-Y$ scores for all participants over time.

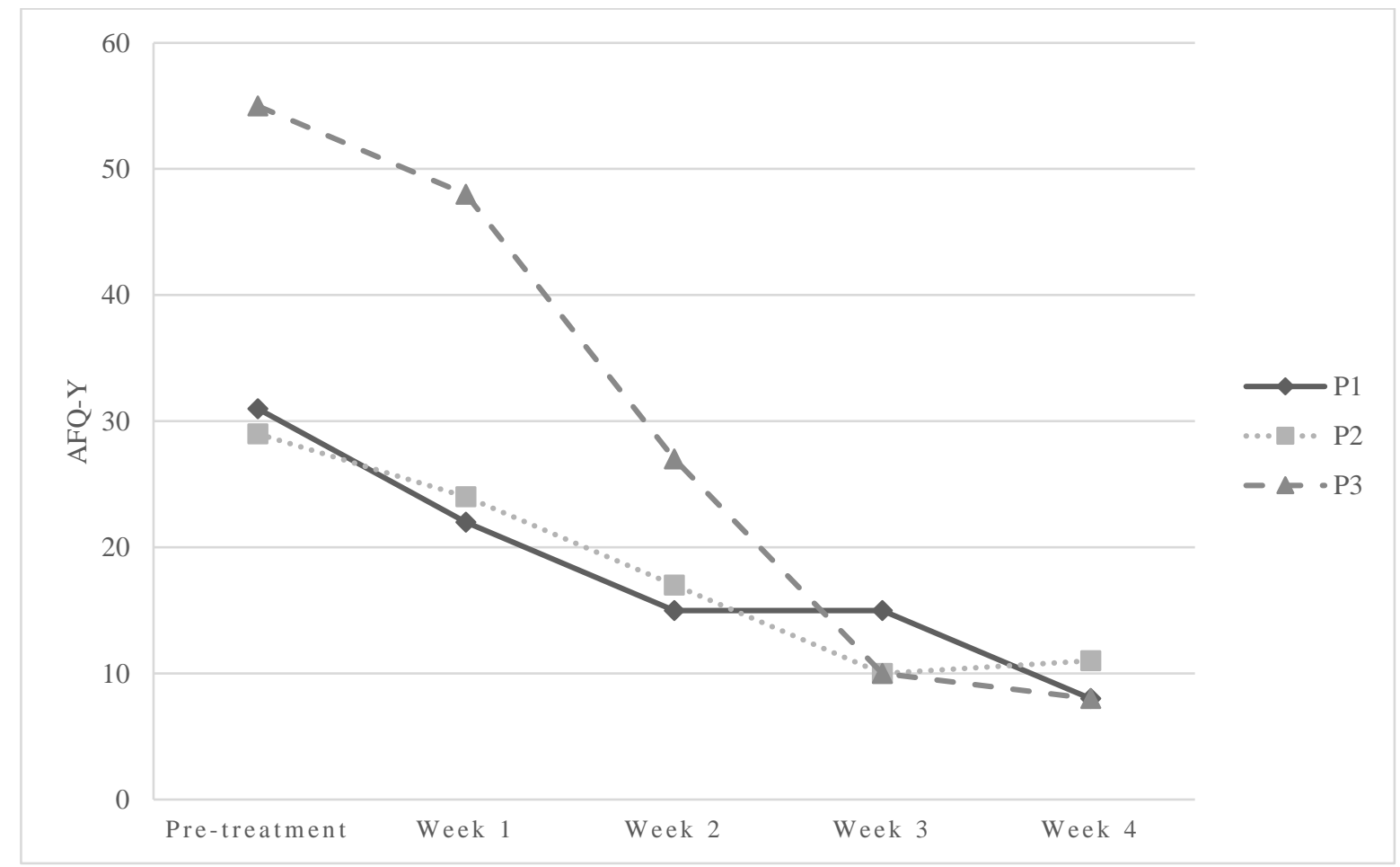

Note. Higher scores indicate greater psychological inflexibility. 
Figure 6

DASS-21 total, depression, anxiety and stress scores over time.

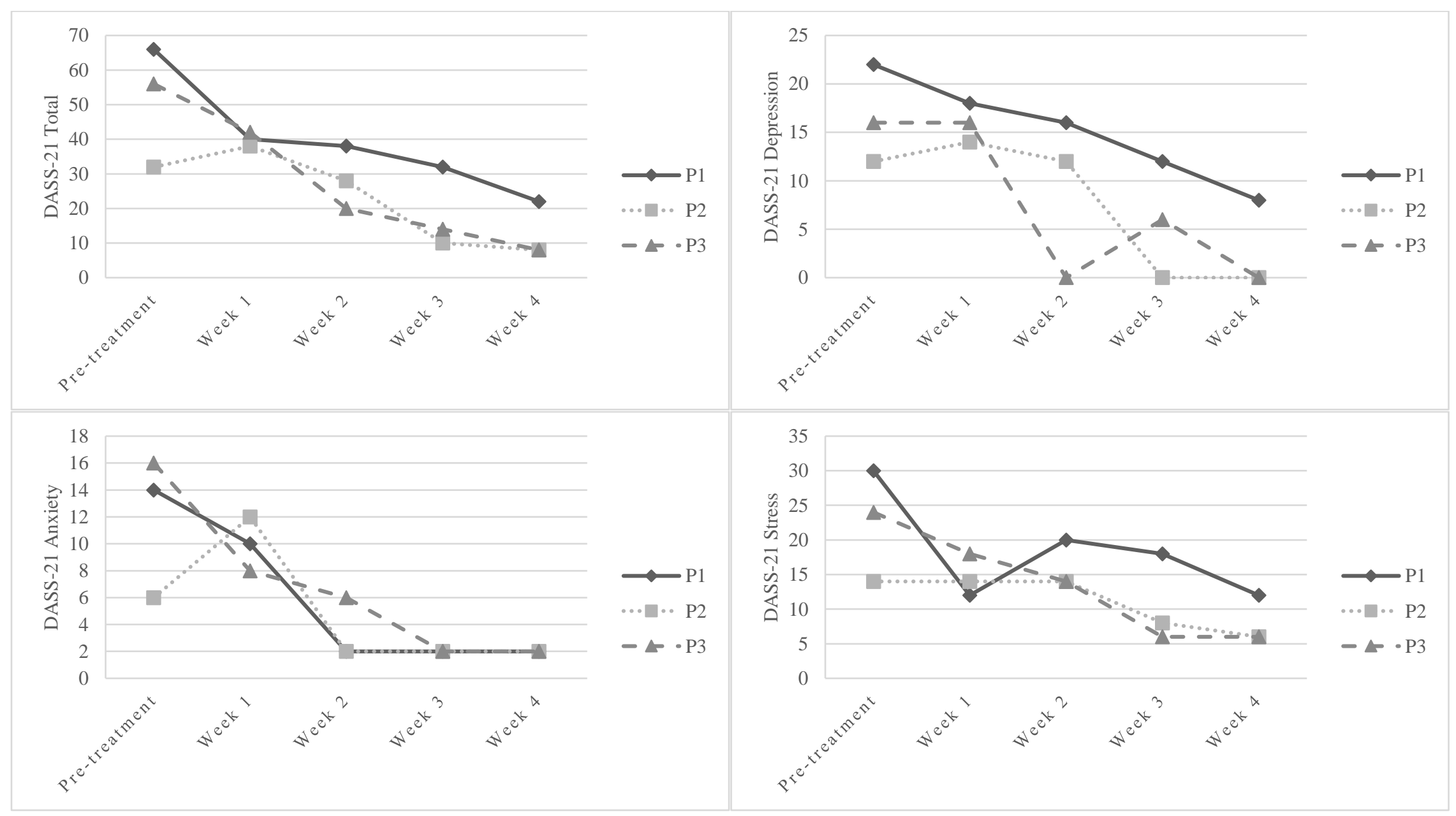

Note. DASS-depression scores of nine and above are considered in the clinical range; 10-13 indicate mild symptoms, 14-20 moderate, 21-27 severe, and greater than 28 as extremely severe. DASS-anxiety scores of seven and above are considered in the clinical range; 8-9 indicate mild symptoms, 10-14 moderate, 15-19 severe, and greater than 20 extremely severe. DASS-stress scores greater than 14 are considered in the clinical range; 15-18 indicate mild stress, 19-25 moderate, 26-33 severe, and greater than 34 extremely severe. 
Table 1

Aggregate means and standard deviations for all three participants at pre-treatment and posttreatment.

\begin{tabular}{lccccc}
\hline Timepoint & C-YBOCS & AFQ-Y & DASS-D & DASS-A & DASS-S \\
M (SD) & M (SD) & M (SD) & M (SD) & M (SD) \\
\hline Pre-treatment & $27.67(1.69)$ & $38.33(11.81)$ & $16.67(4.1)$ & $12(4.32)$ & $22.67(6.59)$ \\
Posttreatment & $14.83(2.24)$ & $9(1.41)$ & $2.67(4.61)$ & $2(0)$ & $8(2.82)$
\end{tabular}

Note. CY-BOCS = Child Yale-Brown Obsessive Compulsive Scale; AFQ-Y = Avoidance and Fusion Questionnaire for Youth; DASS-D = Depression, Anxiety, and Stress Scale - Depression; DASS-A = Depression, Anxiety, and Stress Scale - Anxiety; DASS-S = Depression, Anxiety, and Stress Scale - Stress. 
Table 2

Pre- and post-treatment scores for OCD severity for all participants.

\begin{tabular}{|c|c|c|c|c|c|c|}
\hline \multirow[b]{2}{*}{ Participant } & \multicolumn{2}{|c|}{$\begin{array}{c}\text { CY-BOCS } \\
\text { total }\end{array}$} & \multicolumn{2}{|c|}{$\begin{array}{l}\text { CY-BOCS } \\
\text { obsessions }\end{array}$} & \multicolumn{2}{|c|}{$\begin{array}{c}\text { CY-BOCS } \\
\text { compulsions }\end{array}$} \\
\hline & Pre-treatment & Posttreatment & Pre-treatment & Posttreatment & $\begin{array}{c}\text { Pre- } \\
\text { treatment }\end{array}$ & Posttreatment \\
\hline $\mathrm{P} 1$ & 26 & 17.5 & 13 & 8.5 & 13 & 9 \\
\hline $\mathrm{P} 2$ & 27 & 15 & 13 & 7.5 & 14 & 7.5 \\
\hline P3 & 30 & 12 & 15 & 7 & 15 & 7 \\
\hline
\end{tabular}

Note. Bold scores indicate moderate or severe levels of OCD. CY-BOCS = Child Yale-Brown Obsessive Compulsive Scale. 
Table 3

Pre- and posttreatment scores for all secondary outcomes in all participants.

\begin{tabular}{|c|c|c|c|c|c|c|c|c|c|c|}
\hline \multirow[b]{2}{*}{ Participant } & \multicolumn{2}{|c|}{ AFQ-Y } & \multicolumn{2}{|c|}{$\begin{array}{c}\text { DASS-21 } \\
\text { total }\end{array}$} & \multicolumn{2}{|c|}{$\begin{array}{c}\text { DASS-21 } \\
\text { stress }\end{array}$} & \multicolumn{2}{|c|}{$\begin{array}{c}\text { DASS-21 } \\
\text { anxiety }\end{array}$} & \multicolumn{2}{|c|}{$\begin{array}{c}\text { DASS-21 } \\
\text { depression }\end{array}$} \\
\hline & Pre & Post & Pre & Post & Pre & Post & Pre & Post & Pre & Post \\
\hline $\mathrm{P} 1$ & 31 & 8 & 66 & 22 & 30 & 12 & 14 & 2 & 22 & 8 \\
\hline $\mathrm{P} 2$ & 29 & 11 & 32 & 8 & 14 & 6 & 6 & 2 & 12 & 0 \\
\hline $\mathrm{P} 3$ & 55 & 8 & 56 & 8 & 24 & 6 & 16 & 2 & 16 & 0 \\
\hline
\end{tabular}

Note: Bold values indicate scores in clinical range. AFQ-Y = Avoidance and Fusion Questionnaire for Youth, DASS-21 = Depression, Anxiety and Stress Scale. 


\section{References}

Armstrong, A. B., Morrison, K. L., \& Twohig, M. P. (2013). A preliminary investigation of acceptance and commitment therapy for adolescent obsessive-compulsive disorder. Journal of Cognitive Psychotherapy, 27(2), 175-190.

Bluett, E. J., Homan, K. J., Morrison, K. L., Levin, M. E., \& Twohig, M. P. (2014). Acceptance and commitment therapy for anxiety and OCD spectrum disorders: An empirical review. Journal of Anxiety Disorders, 28(6), 612-624.

Clarke, K., Patterson, P., McDonald, F. E., Wakefield, C. E., Sansom-Daly, U., \& Zebrack, B. (2020). The development and process evaluation of a 3-day acceptance and commitment therapy group program for adolescent cancer survivors. Paper presented at the Child \& Youth Care Forum.

Deacon, B., \& Abramowitz, J. (2006). A pilot study of two-day cognitive-behavioral therapy for panic disorder. Behaviour Research and Therapy, 44(6), 807-817.

Foa, E. B., Yadin, E., \& Lichner, T. K. (2012). Exposure and response (ritual) prevention for obsessive compulsive disorder: Therapist guide: Oxford University Press.

Gallo, K. P., Chan, P. T., Buzzella, B. A., Whitton, S. W., \& Pincus, D. B. (2012). The impact of an 8-day intensive treatment for adolescent panic disorder and agoraphobia on comorbid diagnoses. Behavior Therapy, 43(1), 153-159.

Gaudiano, B. A., Ellenberg, S., Ostrove, B., Johnson, J., Mueser, K. T., Furman, M., \& Miller, I. W. (2020). Feasibility and preliminary effects of implementing acceptance and commitment therapy for inpatients with psychotic-spectrum disorders in a clinical psychiatric intensive care setting. Journal of Cognitive Psychotherapy, 34(1), 80-96. 
Geller, D. A., \& March, J. (2012). Practice parameter for the assessment and treatment of children and adolescents with obsessive-compulsive disorder. Journal of the American Academy of Child \& Adolescent Psychiatry, 51(1), 98-113.

Gloster, A. T., Walder, N., Levin, M., Twohig, M., \& Karekla, M. (2020). The empirical status of acceptance and commitment therapy: A review of meta-analyses. Journal of Contextual Behavioral Science, 18, 181-192.

Guo, S., Rozenman, M., Bennett, S. M., Peris, T. S., \& Bergman, R. L. (2020). Flexible adaptation of evidence-based treatment principles and practices in an intensive outpatient setting for pediatric OCD. Evidence-Based Practice in Child and Adolescent Mental Health, 5(3), 301-321.

Hancock, K. M., Swain, J., Hainsworth, C. J., Dixon, A. L., Koo, S., \& Munro, K. (2018). Acceptance and commitment therapy versus cognitive behavior therapy for children with anxiety: Outcomes of a randomized controlled trial. Journal of Clinical Child \& Adolescent Psychology, 47(2), 296-311.

Hayes, L. L., \& Ciarrochi, J. V. (2015). The thriving adolescent: Using acceptance and commitment therapy and positive psychology to help teens manage emotions, achieve goals, and build connection. New Harbinger Publications.

Jacobson, N. S., \& Truax, P. (1991). Clinical significance: A statistical approach to defining meaningful change in psychotherapy research. Journal of Consulting and Clinical Psychology, 59, 12-19. https://doi.org/10.1037/0022-006X.59.1.12

Kemani, M. K., Kanstrup, M., Jordan, A., Caes, L., \& Gauntlett-Gilbert, J. (2018). Evaluation of an intensive interdisciplinary pain treatment based on acceptance and commitment 
therapy for adolescents with chronic pain and their parents: A nonrandomized clinical trial. Journal of Pediatric Psychology, 43(9), 981-994.

Le, M. T. H., Tran, T. D., Holton, S., Nguyen, H. T., Wolfe, R., \& Fisher, J. (2017). Reliability, convergent validity and factor structure of the DASS-21 in a sample of Vietnamese adolescents. PloS one, 12(7), e0180557.

Levitt, J. T., Brown, T. A., Orsillo, S. M., \& Barlow, D. H. (2004). The effects of acceptance versus suppression of emotion on subjective and psychophysiological response to carbon dioxide challenge in patients with panic disorder. Behavior Therapy, 35(4), 747-766.

Lewin, A. B., Storch, E. A., Merlo, L. J., Adkins, J. W., Murphy, T., \& Geffken, G. A. (2005). Intensive cognitive behavioral therapy for pediatric obsessive compulsive disorder: A treatment protocol for mental health providers. Psychological Services, 2(2), 91.

Lewin, A. B., Piacentini, J., De Nadai, A. S., Jones, A. M., Peris, T. S., Geffken, G. R., ... \& Storch, E. A. (2014). Defining clinical severity in pediatric obsessive-compulsive disorder. Psychological Assessment, 26(2), 679.

Lovibond, S.H. \& Lovibond, P.F. (1995). Manual for the Depression Anxiety \& Stress Scales. (2nd Ed.) Sydney: Psychology Foundation.

McGuire, J. F., Piacentini, J., Lewin, A. B., Brennan, E. A., Murphy, T. K., \& Storch, E. A. (2015). A meta-analysis of cognitive behavior therapy and medication for child obsessive-compulsive disorder: Moderators of treatment efficacy, response, and remission. Depression and Anxiety, 32(8), 580-593.

Micali, N., Heyman, I., Perez, M., Hilton, K., Nakatani, E., Turner, C., \& Mataix-Cols, D. (2010). Long-term outcomes of obsessive-compulsive disorder: Follow-up of 142 children and adolescents. The British Journal of Psychiatry, 197(2), 128-134. 
Ong, C. W., Blakey, S. M., Smith, B. M., Morrison, K. L., Bluett, E. J., Abramowitz, J. S., \& Twohig, M. P. (2020). Moderators and processes of change in traditional exposure and response prevention (ERP) versus acceptance and commitment therapy-informed ERP for obsessive-compulsive disorder. Journal of Obsessive-Compulsive and Related Disorders, 24, 100499.

Öst, L.-G., Riise, E. N., Wergeland, G. J., Hansen, B., \& Kvale, G. (2016). Cognitive behavioral and pharmacological treatments of OCD in children: A systematic review and metaanalysis. Journal of Anxiety Disorders, 43, 58-69.

Reid, A. M., Garner, L. E., Van Kirk, N., Gironda, C., Krompinger, J. W., Brennan, B. P., ... \& Elias, J. A. (2017). How willing are you? Willingness as a predictor of change during treatment of adults with obsessive-compulsive disorder. Depression and Anxiety, 34(11), 1057-1064.

Ronk, F. R., Korman, J. R., Hooke, G. R., \& Page, A. C. (2013). Assessing clinical significance of treatment outcomes using the DASS-21. Psychological Assessment, 25(4), 1103-1110. doi: $10.1037 / \mathrm{a} 0033100$

Shabani, M. J., Mohsenabadi, H., Omidi, A., Lee, E. B., Twohig, M. P., Ahmadvand, A., \& Zanjani, Z. (2019). An Iranian study of group acceptance and commitment therapy versus group cognitive behavioral therapy for adolescents with obsessive-compulsive disorder on an optimal dose of selective serotonin reuptake inhibitors. Journal of ObsessiveCompulsive and Related Disorders, 22, 100440.

Stewart, S. E., Geller, D. A., Jenike, M., Pauls, D., Shaw, D., Mullin, B., \& Faraone, S. V. (2004). Long-term outcome of pediatric obsessive-compulsive disorder: A meta-analysis and qualitative review of the literature. Acta Psychiatrica Scandinavica, 110(1), 4-13. 
Storch, E. A., Geffken, G. R., Merlo, L. J., Mann, G., Duke, D., Munson, M., . . Goodman, W. K. (2007). Family-based cognitive-behavioral therapy for pediatric obsessive-compulsive disorder: Comparison of intensive and weekly approaches. Journal of the American Academy of Child \& Adolescent Psychiatry, 46(4), 469-478.

Storch, E. A., Lewin, A. B., De Nadai, A. S., \& Murphy, T. K. (2010). Defining treatment response and remission in obsessive-compulsive disorder: A signal detection analysis of the Children's Yale-Brown Obsessive Compulsive Scale. Journal of the American Academy of Child \& Adolescent Psychiatry, 49(7), 708-717.

Storch, E. A., Mariaskin, A., \& Murphy, T. K. (2009). Psychotherapy for obsessive-compulsive disorder. Current Psychiatry Reports, 11(4), 296-301.

Twohig, M. P., Abramowitz, J. S., Smith, B. M., Fabricant, L. E., Jacoby, R. J., Morrison, K. L., ... Lederman, T. (2018). Adding acceptance and commitment therapy to exposure and response prevention for obsessive-compulsive disorder: A randomized controlled trial. Behaviour Research and Therapy.

Twohig, M. P., Abramowitz, J. S., Bluett, E. J., Fabricant, L. E., Jacoby, R. J., Morrison, K. L., ... \& Smith, B. M. (2015). Exposure therapy for OCD from an acceptance and commitment therapy (ACT) framework. Journal of Obsessive-Compulsive and Related Disorders, 6, 167-173.

Twohig, M. P., Vilardaga, J. C. P., Levin, M. E., \& Hayes, S. C. (2015). Changes in psychological flexibility during acceptance and commitment therapy for obsessive compulsive disorder. Journal of Contextual Behavioral Science, 4(3), 196-202. 
Twohig, M. P., Hayes, S. C., \& Masuda, A. (2006). Increasing willingness to experience obsessions: Acceptance and commitment therapy as a treatment for obsessive-compulsive disorder. Behavior Therapy, 37(1), 3-13. doi:10.1016/j.beth.2005.02.001

Veale, D., Naismith, I., Miles, S., Gledhill, L. J., Stewart, G., \& Hodsoll, J. (2016). Outcomes for residential or inpatient intensive treatment of obsessive-compulsive disorder: A systematic review and meta-analysis. Journal of Obsessive-Compulsive and Related Disorders, 8, 38-49.

Whiteside, S. P., Brown, A. M., \& Abramowitz, J. S. (2008). Five-day intensive treatment for adolescent OCD: A case series. Journal of Anxiety Disorders, 22(3), 495-504.

Whiteside, S. P., \& Jacobsen, A. B. (2010). An uncontrolled examination of a 5-day intensive treatment for pediatric OCD. Behavior Therapy, 41(3), 414-422.

Willemsen, J., Markey, S., Declercq, F., \& Vanheule, S. (2011). Negative emotionality in a large community sample of adolescents: the factor structure and measurement invariance of the short version of the depression anxiety stress scales (DASS-21). Stress and Health, 27(3), e120-e128.

Zurita Ona, P. (2019). The ACT workbook for teens with OCD: Unhook yourself and live life to the full. Jessica Kingsley Publishers. 